\title{
La Cartoteca del Centro Geográfico del Ejército: 200 años de la creación del Estado Mayor
}

Luis Magallanes Pernas, director técnico del Archivo Cartográfico

\section{HISTORIA INSTITUCIONAL}

Hace 200 años, en plena Guerra de la Independencia, un selecto grupo de militares españoles, encabezado por Joaquín Blake, impulsó la creación del Cuerpo de Estado Mayor del Ejército. Las bases fundamentales en las que se apoya su creación son:

1. Centralizar y conservar los trabajos y noticias de los jefes de los Estados Mayores de los siete ejércitos de operaciones en que se habian articulado nuestras fuerzas militares.

2. Garantizar al ejército español un adecuado nivel de información geográfica y cartográfica, indispensable para la conducción de las operaciones militares.

Una R. 0. del Consejo de Regencia de 9 de junio de 1810 daba vida legal al Cuerpo de Estado Mayor. Formando parte de él, como centro de documentación y estudio, nacía el Depósito de la Guerra que tenía como principal misión la realización, adquisición y conservación de cuantos mapas y planos fueran necesarios para el planeamiento de las acciones militares. Por R. 0 . de 21 de enero de 1847 se aprobó el reglamento para la organización del Depósito de la Guerra. Se componía de dos secciones: una geográfica y topográfica, y otra de historia y estadística militar. Ambas tenían por objeto el reunir, examinar y coleccionar cuantos documentos de las expresadas clases existieran o adquiriera el Depósito. El Depósito de la Guerra fue disuelto por Decreto de 28 de julio de 1931.

Una vez terminada la Guerra Civil, mediante la Orden 29 de diciembre de 1939, se organizó el Servicio Geográfico y Cartográfico del Ejército, que venía a heredar las misiones de la Sección de Geografía y Topografía del Depósito de la Guerra, y se disponía que la Jefatura del mismo se hiciese cargo del archivo geográfico y cartográfico. Esa doble vertiente de organismo productor y archivo cartográfico que está en nuestro origen se sigue manteniendo en la actualidad.

\section{ORIGEN DE LOS FONDOS}

Los fondos proceden, en parte, de la Secretaría del Despacho de Guerra y Hacienda, creada en 1705 por Felipe V. En ella se recogían los documentos formados por el Cuerpo de Ingenieros Mili- tares, fundado en 1711. Estos fondos se incrementaron con los del Cuerpo de Estado Mayor del Ejército, que es, sin duda, la institución con mayor peso en la colección del Archivo.

En 1902, el Depósito de la Guerra adquiria la colección particular de Manuel Rico y Sinobas, Doctor en Medicina y Ciencias Físicas, compuesta por 179 atlas y 2.416 mapas y planos. Un año más tarde, en 1903, el Depósito adquiere otra colección particular, la de Francisco Coello de Portugal, autor del Atlas Geográfico, Histórico
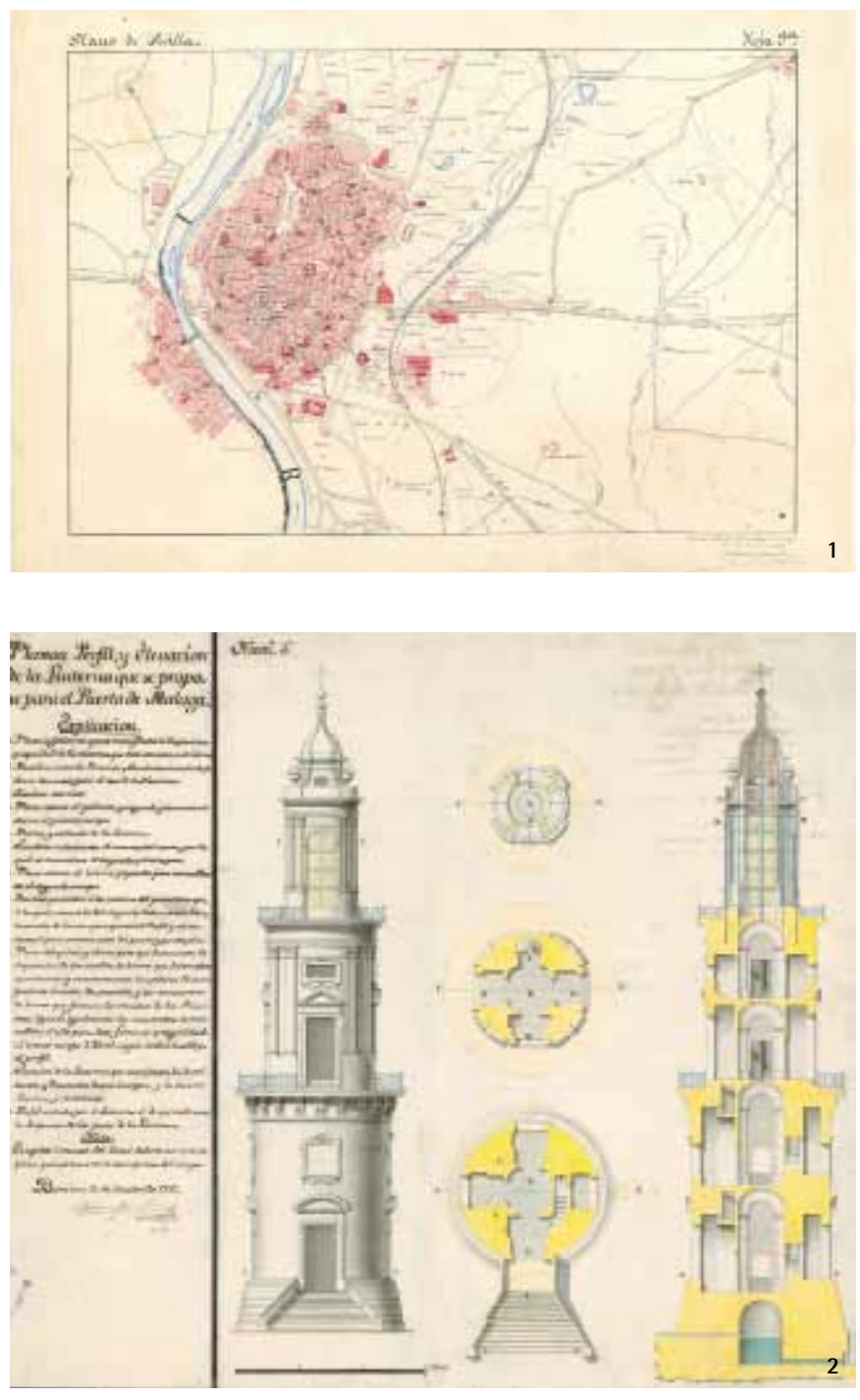

1. Plano de Sevilla. Fuente: Cuerpo de Estado Mayor del Ejército. - 1869. CEGET 414 2. Plano, perfil y elevación de la linterna para el puerto de Málaga. Fuente: Juan Martín Zermeño. - 1772- CEGET 325 
y Estadistico de España y sus posesiones de Ultramar, en colaboración con Pascual Madoz, quien redactó las notas estadísticas.

\section{LA COLECCIÓN GEOGRÁFICA Y CARTOGRÁFICA}

El fondo del Archivo del Centro Geográfico del Ejército está compuesto por 290 atlas y 14.874 mapas y planos, anteriores al siglo $X X$. Desde el punto de vista cronológico, la mayor parte de los documentos corresponden a los siglos XVIII y XIX. En cuanto a la distribución geográfica se puede afirmar que existen documentos de prácticamente todo el mundo, si bien los referidos a España, América, norte de África y Filipinas son mayoritarios.

Con independencia de la documentación cartográfica, el Archivo cuenta con un fondo de 946 memorias y 3.519 itinerarios descriptivos de todo el mundo, principalmente de España, América, Filipinas y Marruecos. La documentación conservada en el Archivo tiene, por su propio proceso de formación, un carácter muy heterogéneo desde el punto de vista geográfico, temático y de los autores de los mapas, aunque entre estos últimos destacan especialmente los organismos e instituciones militares.

A través de la obra de los ingenieros militares podemos valorar el esfuerzo de la Corona española en la articulación del sistema defensivo peninsular y ultramarino (planos de castillos, fuertes, baterias, baluartes, etc.).

La evolución del arte de la guerra en el siglo XIX, con el crecimiento de los frentes de operaciones, provocó el cambio de la cartografía puntual o local a otra territorial o general que requería los métodos de la Topografía apoyada en la Geodesia. A esta última se dedicó el Cuerpo de Estado Mayor, entre cuyas misiones destacó la formación de itinerarios. Mención especial merecen los planos urbanos a los que dedican una atención preferente durante el último tercio del siglo XIX. Realizados sobre el terreno con extraordinario detalle, suponen, en muchos casos, los primeros planos topográficos de nuestras ciudades.

Las colecciones privadas y las adquisiciones del Depósito aportan al fondo la vertiente civil de la cartografia, convirtiéndolo asi en pieza clave no sólo para el estudio de la cartografía militar, sino además para la historia de la Cartografía en general.

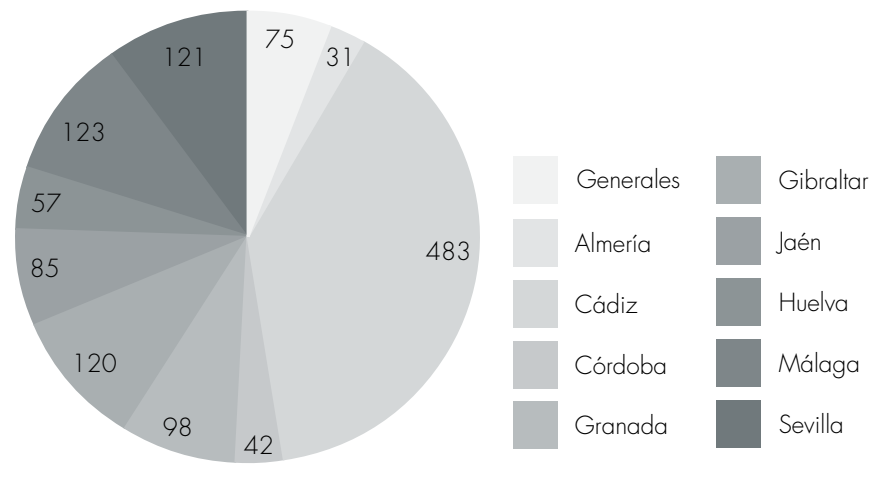

Documentos de Andalucía anteriores al siglo XX en el Archivo del Centro Geográfico del Ejército.

\section{LOS MAPAS DE ANDALUCÍA}

Dentro del fondo de cartografía de España anterior al siglo XX, Andalucía es la comunidad con mayor número de documentos, 1.235. Esta documentación se complementa con 212 memorias geográficas e itinerarios descriptivos.

Como se puede observar en el gráfico, la estratégica situación de Cádiz la convierte en el principal foco de actuación de ingenieros y cartógrafos del Estado Mayor.

La cartografia de Andalucia es fiel reflejo del carácter heterogéneo del fondo del Archivo. Los documentos en su mayoría son manuscritos de los siglos XVIII y XIX. Respecto a la temática, nos encontramos con mapas generales, provinciales, hidrográficos, de batallas, itinerarios, croquis de villas levantados con premura en la Guerra de Independencia, planos de fortificaciones y detallados planos urbanos, entre otros.

Del fondo correspondiente al siglo XX, en proceso de catalogación, Andalucía cuenta con 470 documentos.

En definitiva, un valioso corpus documental, clave para el estudio de la evolución histórica del territorio andaluz.

El mapa más antiguo de Andalucía: el mapa de la provincia romana de la Bética de C. Ptolomeo es la primera representación cartográfica individualizada que se conoce de Andalucía: ıotaavıas ßaıтıкns [Hispania Bætica] Claudio Ptolomeo, mediados del siglo II d. de C., copia de finales del siglo XIV. Manuscrito coloreado sobre pergamino, $16 \times 30 \mathrm{~cm}$. The British Library, Londres, Manuscripts Burney Ms. $111 \mathrm{map} 4 \mathrm{f} .16 \mathrm{v}$. 